\title{
FALASFA
}

\section{PLURALISME DALAM PERSPEKTIF PEMIKIRAN GUS DUR DAN NURCHOLISH MAJID}

\author{
Asripa \\ Devy Habibi Muhammad \\ Ari Susandi \\ Sekolah Tinggi Agama Islam Muhammadiyah Probolinggo \\ Email : Serliasripa12@gmail.com
}

\begin{abstract}
The purpose of this research is to understand the thoughts of Gus Dur and Nurcholish Majid about pluralism. In Indonesian society, which is pluralistic, friction between understandings in various structures of community groups is unavoidable. For this reason, it is important to understand how Gus Dur and Nurcholish Majid think in terms of pluralism. And what are the similarities and differences in their thinking. This study uses a qualitative descriptive approach and the type of research is library research. Data collection comes from several books and scientific works in the form of journals that are relevant to the themes in the research. The data processing in this study was analyzed in accordance with a count approach (statistics) but through the presentation of thoughts, opinions of experts, or information related to the problem. Gus Dur's idea of pluralism has the main goal of creating harmonization of a pluralistic Indonesian society. And according to Nurcholish majid pluralism is a positive value and grace from God to mankind to enrich the growth of diverse cultures.
\end{abstract}

Keywords: Pluralisme, Gus Dur, Nurcholish Majid.

\begin{abstract}
Tujuan dari penelitian ini adalah untuk memhami pemikiran Gus dur dan Nurcholish Majid tentang pluralisme. Dalam masyarakat indonesia yang mejemuk pergesekan antar paham diberbagai struktur kelompok masyarakat tidak dapat dihindari. Untuk itu penting memahami bagaimana pemikiran Gus Dur dan Nurcholish Majid dalam hal pluralisme. Serta apa saja persamaan dan perbedaan dalam pemikiran keduanya. Penelitian ini menggunakan metode pendekatan deskriptif kualitatif dan jenis penelitiannya adalah penelitian kepustakaan (library reseach). Pengumpulan data bersumber dari beberapa buku dan karya ilmiah berupa jurnal yang relevan dengan tema yang ada dalam penelitian. Adapun Pengolahan data dalam penelitian ini dianalisis sesuai dengan pendekatan hitungan (statistik) tetapi memalui penyajian pemikiran,pendapat para ahli, atau informasi yang berhubungan dengan permasalahan. Gasasan pluralisme Gus Dur memiliki tujuan utama yaitu menciptakan harmonisasi masyarakat Indonesia yang majemuk. Dan menurut Nurcholish majid pluralisme merupakan nilai positif dan rahmat dari Tuhan kepada umat manusia untuk memperkaya pertumbuhan budaya yang beraneka ragam.
\end{abstract}

Kata Kunci : Pluralisme, Gus Dur, nurcholish Majid. 
Asripa

Devy Habibi Mubammad

Ari Susandi

\section{PENDAHULUAN}

Indonesia sebagai negara multikultural memiliki penduduk yang sangat beragam. Masyarakatnya yang majemuk terdiri dari berbagai ethnis dan suku, dari segi bahasa terdapat ratusan bahasa yang digunakan di seluruh wilayah nusantara ${ }^{1}$. Dari segi pulau ada 13.000 pulau yang dihuni Indonesia dilatar belakangi puluhan bahkan ratusan sistem kerajaan kesukuan lama yang sangat berpengaruh pada sistem stratifikasi sosial dan adat istiadat yang berlaku hingga saat ini. Dari segi mata pencaharian terdapat keragaman antara kehidupan perkotaan dan pedesaan.Jika dari sisi agama terdapat beberapa agama besar dunia dan sejumlah kepercayaan lokal yang tersebar di seluruh wilyah nusantara ${ }^{2}$.

Bangsa Indonesia sebagai negara yang sedang tumbuh dan memiliki masyarat yang heterogen tentu sulit untuk mengembangkan rasa saling memahami dan pengertian antar berbagai keragaman unsur ethnis,budaya daerah,bahasa ibu, agama dan lain sebagainya.Saat ini rasa saling memahami dan menghormati masyarakat indonesia hanyalah bersifat nominal belaka ${ }^{3}$. Keaadan seperti ini tentunya tidak dapat menjadi pondasi yang kuat untuk bertahan dari berbagai tekanan perkembangan politik, ekonomi, sosial budaya dan teknologi informasi, sehingga kerukunan yang terlihat tenang saat ini merupakan kondisi yang rapuh yang sewaktu-waktudapat berubah menjadi suatu kekacauan ${ }^{4}$.

Jika kita cermati lebih dalam maka kemajemukan bangsa Indonesia merupakan sunnatulah sebagaimana kemajemukan yang ada dimuka bumi ini ${ }^{5}$. Hal ini tercantum dalam Al-quran surat AlHujarat ayat 13 yang memiliki makna bahwa kemajemukan di muka bumi ini adalah kehendak dari Allah SWT. Sedangkan bangsa Indonesia sendiri sebenarnya telah mengetahui tentang wawasan kemajemukan (pluralisme dan multikulturalisme) sejak diciptakanya semboyan Bhineka Tunggal Ika oleh Mpu Tantualar. Serta legitimasi para kaum muda pribumi yang dituangkan dalam ikrar Sumpah Pemuda tahun 1928, serta dicantumkannnya semboyan Bhineka Tunggal Ika dalam lambang garuda pancasila ${ }^{6}$.

\footnotetext{
${ }^{1}$ Nur Khosiah, Reza Hilmi Luayyin, and David Prabowo, "Poligami Perspektif Mubammad Abduh Dan Muhammad Syahrur," Jurnal Imtiyaz 5, no. 02 (2021): 77-86.

2 Laode Monto Bauto, "Perspektif Agama Dan Kebudayaan Dalam Kehidupan Masyarakat Indonesia (Suatu Tinjanan Sosiologi Agama)," Jurnal Pendidikan Ilmu Sosial 23, no. 2 (2016): 11, https://doi.org/10.17509/jpis.v23i2.1616.

3 Ari Susandi, "Pendidikan Life Skills Dalam Penanaman Nilai-Nilai Agama Islam Di Sekolah Dasar," Al-Insyirob: Jurnal Studi Keislaman 6, no. 2 (2020): 95-111, https://doi.org/10.35309/alinsyiroh.v6i2.3867.

${ }^{4}$ Heri Herdiawanto, Fokky Wasitaatmadja Fuad, and Jumanta Hamdayama, Spritualisme Pancasila (Jakarta: Prenadamedia Group, 2018).

${ }^{5}$ Devy Habibi Muhammad, “Implementasi Pendidikan Humanisme Religiusitas Dalam,” Edumaspul Jurnal Pendidikan 4, no. 2 (2020): 122-31.

'Muhammad Fakhri, “Wawasan Kerukunan Beragama Di Indonesia,” Jurnal Toleransi 1, no. 2 (2009): 141.
} 
Mengamati fenomena disharmonis dari kemajemukan bangsa indonesia maka masyarakat indonesia harus bertransformasi menjadi insan yang lebih humanisme ${ }^{7}$. Humanisme merupakan sikap yang lebih terbuka terhadap prinsip hidup orang lain.hal ini berarti kita dituntut untuk memiliki simpati dan empati terhadap kesulitan yang dialami orang lain, agar kita dapat memberikan kasih sayang yang melampaui garis primodial dan sekat-sekat sosial yang membatasi. Humanisme ini melambangkan cinta keadilan dan keberimbangan (fairness). Setelah memahami tentang perbedaan prinsip maka akan melahirkan sikap tenggang rasa dan sikap toleransi terhadap keberagaman yang ada disekitarnya (pluralisme), sehingga tercipta kerukunan dan kedamaian hidup dalam perbedaan yang ada.

Berdasarkan latar belakang tersebut diatas penulis merumuskan masalah penelitian ini, yaitu 1) Bagaimana pemikiran Gus Dur dalam hal pluralisme? 2) Bagaimana pemikiran Nurcholish Majid dalam hal pluralisme? 3) apa saja persamaan serta perbedaan pandangan antara Gus Dur dan Nurcholish Majid?. Penelitian ini bertujuan 1) Untuk mengetahui pemikiran Gus Dur dalam hal pluralisme 2) Untuk mengetahui pemikiran Nurcholish Majid dalam hal pluralisme 3) Untuk mengetahui apa saja persamaan serta perbedaan pandangan antara Gus Dur dan Nurcholish Majid.

\section{PEMBAHASAN DAN HASIL}

Plurarisme adalah bentuk masyarakat majemuk yang berkaitan dengan sistem sosial, politik dan kebudayaan yang berbeda di dalam stuktur masyarakat". Pluralisme jika dipandang dari sudut filsafat, pluralisme merupakan pandangan yang mengakui bahwa hakikatnya dalam dunia ini terdapat banyak unsur.Hal ini bertentangan dengan monoisme yang menekankan kesatuan di dalam banyak hal atau dualisme yang berarti dunia ini terdiri dari dua hal yang berbeda ${ }^{10}$.

Pluralisme sebagai paham dan pandangan hidup juga mengakui dan menerima keberagaman dan kemajemukan dalam suatu kelompok masyarakat, maksudnya adalah menerima kemajemukan dari berbagai segi diantaranya dari segi agama, suku, ras dan adat istiadat. Kemudian inilah yang menjadi dasar terbentuknya bermacam- macam kelompok kecil yang terbatas dan mempunyai ragam ciri khas

\footnotetext{
${ }^{7}$ Cik Naimah and Ulil Hidayah, "Reorientasi Pendidikan Islam Untuk Harmonisasi Sosial: Hidden Curriculum Sebagai Sebuah Tawaran," Proceedings of Annual Conference for Muslim Scholars, no. Seri 2 (2017): 726-32, http://proceedings.kopertais4.or.id/index.php/ancoms/article/view/73.

${ }^{8}$ Sarno Hanipudin and Afif Anasrullah Alhaq, "Pemikiran Pendidikan Pluralisme KH. Abdurrahman Wabid," Jurnal Insania 22, no. 1 (2017): 38 .

${ }^{9}$ Eko Handoyo, Studi Masyarakat Indonesia (Semarang: Penerbit Ombak, 2015).

${ }^{10}$ Tri Wahyudi Ramdhan, "Islam Nusantara : Pribumisasi Islam Ala NU," Al-Insyiroh: Jurnal Studi Keislaman 2, no. Islamic Studies (2018):73-91, http://ejournal.kopertais4.or.id/madura/index.php/alinsyiroh/article/view/3333.

77 | Falasifa, Vol. 12 Nomor 2 September 2021
} 
Asripa

Devy Habibi Mubammad

Ari Susandi

tertentu untuk membedakan dengan kelompok- kelompok lain dalam suatu masyarakat yang majemuk, seperti kelompok keagaman,suku dan ras yang memiliki budaya dan adat istiadat beraneka ${ }^{11}$.

Dalam masyarakat majemuk, yang dapat menerima perbedaan bukan berarti menyamaratakan perbedaan tersebut melainkan meyakini bahwa tedapat hal- hal yang berbeda yang tidak dapat disamaratakan. Adanya perbedaan ini menjadikan pluralisme menemukan jati dirinya untuk membangun dan menciptakan toleransi serta mendamaikan suasana ditengah perbedaan ${ }^{12}$.

Dalam hal tolereansi ini Rosullulah telah mencontohkan sebagaimana dikisahkan oleh Ibnul ishak dalam "sirahnya" dan Ibnul Qoyyim dalam "Zaadul Ma'ad” bahwasanya ketika datang utusan Nasrani dari Najran yang jumlahnya 60 orang dan 14 orang diantaranya adalah orang-orang terkemuka termasuk didalamnya Abu Haritsah Al-qomah sebagai seorang guru dan uskup. Adapun maksud kedatangan mereka ialah ingin mengenal secara dekat siapa dan bagaimanakah ajaran yang dibawa Nabi Muhammad, mereka ingin membandingkan ajaran Islam dan Nasrani, mereka juga ingin membahas tentang berbagai masalah agama. Kedatangan mereka di Madinah bertepatan dengan kaum muslimin yang telah melaksanakan ibadah sholat ashar, kemudian merekapun sampai dimasjid dan ingin melaksanakan ibadah sesuai dengan cara mereka di dalam masjid, para sahabatpun heboh dan Rosulullah yang mengetahui hal tersebut berkata "biarkanlah" maka mereka melaksanakan sembahyang dengan cara mereka dalam masjid madinah serta menggunakan jubah kepedetaan yang serba mentereng dan selempang berwarna-warni yang merupakan baju kebesarannya. Kisah ini menunjukkan betapa Nabi Muhammad sangat toleran terhadap pemeluk agama lain ${ }^{13}$.

Pluralisme di negara kita tersirat dalam motto Bhineka Tunggal Ika yang berarti bahwa Indonesia memiliki berbagai pulau, suku bangsa, ras dan agama tetapi tetap satu jua yaitu indonesia.sebab itulah indonesia memerlukan konsep pluralisme untuk tetap menjaga dan mempertahankan rasa persatuan dan kesatuan ${ }^{14}$.

\section{Pluralisme dalam perspektif pemikiran Gus Dur}

Abdurrahman Wahid atau akrab disapa Gus dur lahir di desa Denanyar Jombang, Jawa Timur pada tanggal 7 september 1940. Ia merupakan putra pertama dari enam bersaudara. Gus Dur, cucu dari KH.Hasyim asy'ari yang mendirikan organisasi besar keagamaan yaitu Nahdlatul Ulama (NU). Ayah

11 Mohammad Fahrur Rozi, "PLURALISME DAN MULTIKULTURALISME DALAM MEMBANGUN MASYARAKAT MADANI; KAJIAN PARADIGMATIK," JUmal Al-Ibrah 11, no. 5 (2107).

${ }^{12}$ Muhadis Azzuhri, "KONSEP MULTIKULTURALISME DAN PLURALISME DALAM PENDIDIKAN AGAMA," Tarbibyah 10, no. 9 (2012): 47-48.

${ }^{13}$ Fakhri, "Wawasan Kerukunan Beragama Di Indonesia."

${ }^{14}$ rozi, "Pluralisme Dan Multikulturalisme Dalam Membangun Masyarakat Madani; Kajian Paradigmatik." 
beliau KH.Wahid Hasyim adalah seorang kyai yang pernah menjabat menteri agama, sedangkan ibu neliau Hj.Sholehah adalah putri dari KH.Bisri Syansuri pendiri pondok pesantren Denanyar Jombang ${ }^{15}$.

Pendidikan Gus Dur berawal dari sekolah Dasar (SD) di jakarta. Tahun 1954 Ia mulai Sekolah Menengah Ekonomi Pertama (SMEP), namun karena Gus Dur tidak naik kelas maka di tahun itu juga sang ibu yang berstatus janda dan harus berjuang sendiri membesarkan anak-anaknya mengirim Gus Dur ke Yogyakarta untuk meneruskan sekolah menengah pertamanya. Di Yogyakarta Gus Dur menetap dirumah salah satu sahabat ayahnya yaitu Kyai Juanidi yang tercatat sebagai anggota Majelis Tarjih Muhammadiyah. Dalam menyempurnakan pendidikannya Ia juga menuntut ilmu di pesantren Al-Munawir sebanyak tiga kali dalam setiap minggu. Pesantren ini terletak di Krapyak yang berada di luar kota Yogyakarta ${ }^{16}$.

Tamat dari Sekolah Menengah Ekonomi Pertama (SMEP) di Yogyakarta pada tahun 1957, Gus Dur aktif mendalami ilmu di pesantren secara penuh. Ia belajar di pesantren Tegalrejo di Magelang, yang letaknya di sebelah utara Yogyakarta. Ia belajar kepada kyai Khudori yang merupakan salah satu pemuka NU. Dari beliaulah Gus Dur mulai mengenal ritus-ritus sufi dan ditanamkan praktek ritual mistik. Gus Dur mulai mengadakan perjalanan ziarah ke kuburan-kuburan keramat para wali di tanah jawa dan atas bimbingan serta arahan dari sang kyai Khudori ${ }^{17}$.

Gus Dur menuju ke Kairo-Mesir pada tahun 1963 bulan november untuk meneruskan belajarnya di universitas $\mathrm{Al}$-azhar setelah mendapat beasiswa dari menteri agama, namun karena tidak memiliki ijazah dari pesantren, meskipun Ia telah lulus dari berbagai studi di pesantren maka menurut pejabat universiras tersebut Ia harus mengikuti kela khusus untuk mengetahui kemampuan bahasa arabnya ${ }^{18}$.

Di Mesir Gus Dur merasa beruntung karena kebebasan untuk mengeluarkan pendapat mendapatkan perlindungan yang cukup baik dari pemerintah setempat. Saat itu Mesir berada dibawah kepemimpinan Presiden Gamal Abdul Nasser, seorang nasionalis yang dinamis dan pada saat itu juga Kairo menjadi era keemasan kaum intelektual. Tahun 1966 Ia pindah ke Irak, saat itu Irak berada pada sebuah peradaban modern yang mengusai kebudayaan islam yang cukup modern. Tahun 1970 Ia pun memasuki Departement Of Religion di universitas Bagdhad. Pengalaman hidup selama di Bagdhad terasa berbeda dengan yang di alaminya saat di Mesir.di Bagdhad ia merasa lebih mendapatkan rangsangan intelektual yang tidak ia dapatkan saat berada di Mesir. Selesai menempuh ujian S2, Ia

\footnotetext{
15 Safrizal Rambe, Sang Penggerak Nabdlatul Ulama K.H. Abdul Wabab Chasbullah Sebuah Biografi (Jakarta: Madani Institute, 2020), http://www.elsevier.com/locate/scp.

${ }^{16}$ Azzuhri, "KONSEP MULTIKULTURALISME DAN PLURALISME DALAM PENDIDIKAN AGAMA."

17 oman Fathurrahman, "Sejarah Pengkafiran Dan Marginalisasi Paham Keagamaan Di Melayu Dan Jawa," Jurnal Analisis XI (2011): 447-74.

${ }^{18}$ Hanipudin and Alhaq, "Pemikiran Pendidikan Pluralisme KH. Abdurrahman Wahid."

79 | Falasifa, Vol. 12 Nomor 2 September 2021
} 
Asripa

Devy Habibi Mubammad

Ari Susandi

memiliki keinginan untuk melanjutkan kuliah S3 di Eropa, tapi terkendala penguasaan bahasa eropa sehingga pada tahun 1970-1971 ia menghabiskan waktu berkeliling eropa hanya untuk belajar bahasa Perancis, Inggris dan Jerman. Akhirnya Gus Dur menetap di Belanda sema enam bulan dan mendirikan Perkumpulan Pelajar Muslim Indonesia dan Malaysia yang bearada di Eropa.Selain itu ia juga pergi ke Mc Gill University di kanada untuk mendalami kajian-kajian islam ${ }^{19}$.

Tahun 1971 Gus Dur pulang ke Indonesia dan langsung kembali ke jombang, Ia mengajar di Fakultas Ushuluddin universitas Tebuireng Jombang. Tiga tahun kemudian ia menjadi sekretaris pesantren Tebuireng, ia juga mulai aktif menulis dan lewat tulisan-tulisannya, ia tuangkan gagasan dan pemikirannnya sehingga ia mendapatkan banyak perhatian khalayak sejak pertengahan 1970-an (hamidah, 2011). Dan sebelumnya Ia sudah berkomunikasi dengan Cak Nur dan Djohan efendi maka saat Ia berada di jakarta Ia semakin sering bergabung dalam kegiatan form akademik dalam kelompokkelompok kajian ${ }^{20}$.

Dari gambaran perjalanan hidup Gus Dur dalam meniti kehidupannya, ia bertemu dengan berbagai macam orang dengan latar belakang yang berbeda dari segi budaya, kepentingan, ideology, strata sosial, dan pemikiran. Dari segi kultural, Ia pernah berada diantara adat ketimuran yang santun, tertutup, dan ramah hingga peradapan barat yang terbuka, modern dan liberal. Dari segi pemahaman keagaman dan ideologi, ia pernah melintasi kehidupan yang tradisionalis, ideologis, fundamentalis sampai modernis dan sekuler. Ia juga pernah bersentuhan dengan para pemikir yang konservatif, ortodoks sampai dengan pemikir yang liberal dan radikal, itulah mengapa Gus Dur terlihat dinamis dan sulit dipahami. Kebebasan dan keluasan cakrawala berpikirnya melewati batas-batas tradisionalisme komunitasnya ${ }^{21}$.

Gagasan Gus Dur sebagai salah satu cendikiawan muslim yang merespon berbagai masalah ditanah air diantaranya adalah Pribumisasi islam, demokrasi dan hak asasi manusia. Pribumisasi islam merupakan proses akulturasi nilai-nilai budaya asli suatu wilayah dengan nilai-nilai budaya yang ada di dalam agama islam. Pribumisasai islam dapat dilakukan dengan cara tetap melestarikan budaya atau tetap menjalankan budaya yang sudah ada tanpa mempermasalahkan berasal dari latar belakang agama

\footnotetext{
${ }^{19}$ M.Wahid Nur Tualeka, "Gerakan Neomodernisme Islam Di Indonesia," AL-Hikmab: Jurnal Studi Agama-Agama 1, no. 1 (2015): 1689-99.

20 Rozi, "PLURALISME DAN MULTIKULTURALISME DALAM MEMBANGUN MASYARAKAT MADANI; KAJIAN PARADIGMATIK."

${ }^{21}$ Azzuhri, "KONSEP MULTIKULTURALISME DAN PLURALISME DALAM PENDIDIKAN AGAMA."
} 
selain islam, selama budaya tersebut menghadirkan kebaikan dan dapat menciptakan kerukunan hidup umat beragama ${ }^{22}$.

Agama islam bagi Gus Dur merupakan petunjuk dalam membangun gagasan dan wacana pribumisasi islam. Hal tersebut merupakan sikap penolakan Gus Dur terhadap hegemoni arabisasi. Pokok utama dalam pandangannya mengenai hal tersebut adalah bagaimana islam sebagai suatu ajaran normatif yang berasal dari Tuhan dapat diakomodasikan terhadap kebudayaan yang berasal dari manusia tanpa menghilangkan identitas masing-masing. Menurut Gus Dur “ Proses mengindifikasi diri dengan kebudayaan Timur Tengah (Arabisasi) merupakan tercabutnya budaya kita dari akar budaya kita sendiri, dan lebih dari itu Arabisasi belum tentu cocok dengan kebutuhan", sehingga islam tetap menjadi akomodatif tanpa meremehkan budaya lokal. Dalam hal ini Gus Dur ingin mencoba melepaskan paket ajaran islam yang sampai ke indonesia dari unsur lokal Arab dan diganti menjadi lokal Indonesia. (al-ma'ruf, 2019).Masyarakat Indonesia yang sopan dan santun merupakan salah satu ciri khas yang bisa menjadi modal utama dalam konsep toleransi yang saat ini semakin tidak "terngiang" lagi. Inti dari pribumisasi islam adalah kebutuhan, bukan untuk menghindari polarisasi antara agama dengan budaya, karena polarisasi memang tidak dapat dihindari ${ }^{23}$.

Gagasan demokrasi Gus Dur telah dikenal publik jauh sebelum Gus Dur menjadi Presiden RI yang ke empat. Didalamnya terdapat nilai persamaan dan kebebasan yang berjalan seiring dengan pluralitas bangsa Indonesia. Dalam demokrasi semua warga negara bisa meningkatkan kreatifitasnya dan berusaha menyelaraskan pemikiran serta bijaksana walaupun ada perbedaan pandangan. Maka dalam gagasan pemikiran Gus Dur perlu adanya upaya yang harus dilakukan agar dapat saling memaklumi makna demokrasi yang utuh, tanpa mengharuskan adanya kesamaan atau keseragaman sikap $^{24}$

Demokrasi menurut Gus Dur adalah pilihan yang harus dijalani dan menghidupkan demokrasi secara penuh merupakan keinginannya meskipun demokrasi memerlukan waktu dan proses yang panjang. Gus Dur menempatkan islam dan demokrasi pancasila dengan seimbang. Dimana Islam menjadi kaidah pedoman kehidupan masyarakat dan demokrasi pancasila sebagai landasan konstituonal. Dalam dunia perkembangan modern saat ini, demokrasi mampu menyatukan beragam arah kecenderungan kekuatan-kekuatan bangsa menjadi berputar bersama-sama menuju kedewasaan,

\footnotetext{
${ }^{22}$ N Romania, "Konstruksi Pengurus Pimpinan Wilayah Gerakan Pemuda Ansor Jawa Timurtentang Pluralisme Agama Menurut Gus Dur," Kajian Moral Dan Kewarganegaraan 3, no. 4 (2016): 1391-1407, https://jurnalmahasiswa.unesa.ac.id/index.php/jurnal-pendidikan-kewarganegaraa/article/viewFile/16505/14997.

${ }^{23}$ Tri Wahyudi Ramdhan, "Islam Nusantara : Pribumisasi Islam Ala NU."

24 Listiana, Akhmad Fatikhul Amin Abdullah, and Widjijanto, "PEMIKIRAN KH. ABDURRAHMAN WAHID TENTANG PLURALISME AGAMA DI INDONESIA TAHUN 1999-2001 (KH.," Jurnal Program Studi Sejarah STKIP PGRI Sidoarjo 2, no. 2 (2014): 264-80.
}

81 | Falasifa, Vol. 12 Nomor 2 September 2021 
Asripa

Devy Habibi Mubammad

Ari Susandi

kemajuan dan intergeritas bangsa. Upaya mencapai kehidupan yang demokratis dalam masyarakat majemuk dengan adanya tindakan dari seluruh elemen masyarakat bukan hanya menyerahkan sepenuhnya pada pemerintah ${ }^{25}$.

Pandangan Gus Dur tentang Hak Asasi manusia yang terus berkembang seiring dengan intensitas kesadaran manusia atas hak dan kewajiban yang dimilikinya. Sehingga wacana ini menjadi hal paling mendasar yang diperjuangkan Gus Dur secara konsisten, yaitu hubungan antara individu dan masyarakat. Ia berpendapat bahwa tingginya kedudukan manusia dalam kehidupannya menyebabkan manusia sebagai individu harus mendapatkan perlakuan yang seimbang. Karenanya individu memiliki hak-hak dasar yang tidak dapat dilanggar. Kemudian hak-hak ini disebut sebagai hak-hak asai manusia yang menyangkut perlindungan hukum, penyediaan kebutuhan pokok, perlakuan adil, peningkatan kecerdasan dan kebebasan keyakinan dan keimanan ${ }^{26}$.

Demi tegaknya pluralisme dalam masyarakat menurut Gus Dur bukan hanya terletak pada suatu pola hidup berdampingan secara damai, sebab hal ini masih rentan munculnya kesalahpahaman antar kelompok masyarakat yang pada akhirnya menimbulkan disintragasi. Dalam pluralisme harus ada kesadaran untuk saling mengenal dan berdialog dengan tulus sehingga timbul take and give antar kelompok $^{27}$.

Gasasan pluralisme Gus Dur memiliki tujuan utama yaitu menghadirkan harmonisasi masyarakat Indonesia yang majemuk. Imbas dari pemikirannya ini, membuat Ia harus berada di garda depan saat ada oknum-oknum yang ingin mencidrai kebhinekaan negeri ini, baginya kebhinekaan adalah sunatullah dan tidak satu pihakpun boleh mengubahnya. Jika keanekaragaman dikelola dengan baik maka akan memunculkan rasa saling menghargai dan menghormati sehingga harmonisasi dapat terwujud dikalangan anak bangsa. Gus Dur merupakan tokoh yang terbuka terhadap perkermbangan intelektual, ia respektif kepada orang yang menganut agama lain, dan tetap kokoh keyakinannya pada ajaran islam. Ia menghargai secara penuh keyakinan orang lain, tapi tetap kuat kepada keyakinan tuntunan agama islam, Ia pun mudah bergaul dengan pemeluk agama lain yang ada di nergeri ini ${ }^{28}$.

\footnotetext{
${ }^{25}$ Akhmad Rijal, "Analisa Pemikiran Demokrasi Di Indonesia(Studi Pemikiran Abdurrahman Wahid Dan Nurcholish Majid)," Jurnal Khitab:Kajian Islam ,Budaya Dan Humaniora 4, no. 2 (2021).

${ }^{26}$ H Nurdin, "Upaya Pemerintah Dalam Menghormati Dan Melindungi Ham Dengan Konsep the Rule of Law," Meraja Journal 1, no. 2 (2018): 9-15.

${ }^{27}$ Hanipudin and Alhaq, "Pemikiran Pendidikan Pluralisme KH. Abdurrahman Wahid."

${ }^{28}$ Hanipudin and Alhaq.
} 


\section{Pluralisme dalam perspektif Nurcholish Majid}

Nurcholish Majid terlahir di Mojoanyar, Jombang Jawa timur pada tanggal 17 maret 1939. Ia adalah sosok santri yang ayahnya memiliki hubungan dekat dengan KH.Hasyim asy'ari yang merupakan pendiri NU. Ibunya juga berasal dari kalangan NU, Nurcholish Majid juga merupakan adik dari seorang Rais Akbar NU, dan ayahnya juga seorang aktivis Sarekat Dagang Islam (SDI) di Kediri Jawa Timur. Tahun 1955 Nurcholish Majid belajar di Pesantren Darussalam Gontor dan Gontor merupakan tempat yang memberinya ispirasi terhadap pokok- pokok pikirannya yang kemudian menjadi corak pemikirannya. Tiga hal pokok itu adalah modernisasi, non-sektarianisme, dan pluralisme ${ }^{29}$.

Dalam pesantren ini pluralisme cukup terjaga, ini terbukti dengan adanya izin bagi santri untuk bergaul dengan orang-orang NU maupun Muhammadiyyah. Suasana yang kondusif ini membuat Nurcholish Majid merasa nyaman belajar di pesantren ini. Di ponpes Darussalam Nurcholish Majid dikenal sebagai santri yang berprestasi membuat KH.Zarkasyi sebagai pimpinan dipesantren tersebut berkeinginan mengirim Nurcholish Majid ke Universitas Al-Azhar, Kairo. Namun karena masa itu terjadi ( krisis Terusan Suez) sehingga Ia gagal untuk berangkat ${ }^{30}$.

Iapun kemudian mengajar selama satu tahun di Gontor, setelah itu Ia mendaftarkan diri sebagai mahasiswa di IAIN Jakarta. Kemudian ia melanjutkan studinya di Chigago, Amerika serikat. Tahun 1984 Ia meraih gelar Pbilosopy Doctoral (Ph.D) di universitas Chigago dengan predikat cumlaude. Dan disertasinya Ia mengankat pemikiran Ibnu Taymiyah dengan judul "Ibn Taymiyah dalam ilmu kalam dan filsafat masalah akal dan wahyu dalam islam ${ }^{31}$.

Nurcholish Majid adalah Cendikiawan Muslim yang juga memiliki pandangan cukup luas tentang pluralisme. Ia sering menghubungkan pluralisme dengan legalisme penegakan masyarakat madani (civil society). Selain itu Ia dikenal sebagai seorang yang dapat menganalisa bahasa dengan menarik berdasarkan teologis historis yang cukup mengakar dengan pertimbangan dimensi transendental, etis dan sosial ${ }^{32}$.

Merujuk pada masyarakat yang dibangun oleh Rosullah SAW, yang mempertimbangkan dimensi tradensental, etis, dan sosial, Nurcholish Majid meminjam istilah (ekspirimen Madinah) untuk menegakkan civil society yang memiliki karakteristik egaliterisme. Menurutnya, dalam eksperimen madinah ini Rosullulah memberikan contoh kepada segenap manusia tentang mengelola sosial pilitik.

\footnotetext{
${ }^{29}$ Rozi, "PLURALISME DAN MULTIKULTURALISME DALAM MEMBANGUN MASYARAKAT MADANI; KAJIAN PARADIGMATIK."

${ }^{30}$ Sigit Priambodo, "Motif Intervensi Arab Saudi Terhadap Perang Saudara Di Yaman," Jurnal Analisis Hubungan Internasional 6, no. 1 (2017): 205-16, http://journal.unair.ac.id/download-fullpapers-jahi0e78990c98full.pdf.

${ }^{31}$ Rijal, "Analisa Pemikiran Demokrasi Di Indonesia(Studi Pemikiran Abdurrahman Wahid Dan Nurcholish Majid)."

32 Rozi, "PlURALISME DAN MULTIKULTURALISME DALAM MEMBANGUN MASYARAKAT MADANI; KAJIAN PARADIGMATIK."
}

83 | Falasifa, Vol. 12 Nomor 2 September 2021 
Asripa

Devy Habibi Mubammad

Ari Susandi

Kehidupan masyarakat Madinah pada masa Rosullah ini dimaknai Nurcholish Majid sebagai strategi untuk mempermudah islam di Indonesia untuk menerima secara utuh sistem Pancasila. Mengingat sampai saat ini masih terjadi perdebatan Islam dan Pancasila dan ini tidak boleh dibiarkan terus menerus, sebab islam dan pancasila tidak boleh diperdebatkan karena hal ini sudah final sebagaimana piagam Madinah yang telah dikonsepsikan Rosulullah dan rakyatnya ${ }^{33}$.

Pemikiran dan gasasan Nurcholish Majid yang banyak dikenal dan mampu melahirkan pengaruh terhadap perubahan-perubahan tertentu dalam masyarakat Indonesia yaitu keadilan sosial, sebagaimana yang dicontohkan Rosulullah SAW dan para sahabatnya. Umat islam tidak menghendaki sesuatu melainkan kebaikan bersama. Kebaikan itu bukan hanya untuk kepentingan diri sendiri dan kelompoknya saja, karena agama islam adalah rahmatan lil alamin untuk semua makhluk di dunia. Kebaikan tersebut berlaku untuk kemaslahatan seluruh alam termasuk semua makhluk hidup dan dunia beserta isinya. Bagi umat islam pemikiran tentang etika asasi mendasari pengambilan sebuah keputusan dalam bertindak, termasuk dalam bidang sosial-politik yang tercakup dalam ajaran-ajaran universal islam. Berdasarkan etika asasi inilah kaum muslim memilih pandangan sosial-politik untuk menopang usahanya demi mewujudkan cita-citanya dalam menciptakan kebaikan untuk semua ${ }^{34}$.

Hal ini serupa dengan pandangan Al-Quran, secara individual Al-Quran bertujuan menanamkan keshalehan yang baik atau biasa disebut taqwa. Secara sosial Al-Quran berupaya menciptakan tatanan sosial berbasis etika dan keduanya harus saling berkesinambungan, karena dalam Al-Quran terdapat ajaran sosial-politik yang mengajak agar "mengadakan” perbuatan baik dan menyingkirkan kedholiman di muka bumi ini. Maka dari itu prinsip reformasi pertama ialah egalitarisme kemanuasian ${ }^{35}$.

Konsepsi keadilan yang merupakan warisan sejarah sebenarnya telah dimulai ribuan tahun yang lalu. Keadilan disini harus ditempatkan pada perspektif yang sebenarnya dan keadilan dapat menghapus sistem dinasti atau sistem genologi. Dalam bidang hukum " hukum di larang memihak terhadap seorang yang berpengaruh atau seorang yang berkuasa tapi peraturan ini berlaku bagi semua anggota masyarakat tanpa terkecuali" 36 .

Mengadaptasi pandangan Murtadha Mutahari, Nurcholish Majid membagi keadilan menjadi beberapa bagian yaitu pertama, keadilan yang mendasari pertimbangan atau seimbang (mauqun,balanced). Kedua, keadilan yang memiliki arti persamaan (muswah,egaliter) dan ketiga keadilan yang utuh dengan memberikan hak kepada siapa yang berhak. Dan kedholiman dalam makna merampas hak dari orang

33 Irfan Efendi, "Pluralisme Dalam Pendidikan Islam: Studi Pemikiran Prof. Dr. Nurcholish Madjid," Progresiva: Jurnal Pemikiran Dan Pendidikan Islam 7, no. 2 (2018): 114, https://doi.org/10.22219/progresiva.v7i2.13976.

${ }^{34}$ Achmad Suhaili, "Hak Asasi Manusia (HAM) Dalam Penerapan Hukum Islam Di Indonesia," Al-Bayan: Jurnal Ilmu AlQur'an Dan Hadist 2, no. 2 (2019): 176-93, https://doi.org/10.35132/albayan.v2i2.77.

${ }^{35}$ Tualeka, "Gerakan Neomodernisme Islam Di Indonesia."

${ }^{36}$ Suhaili, "Hak Asasi Manusia (HAM) Dalam Penerapan Hukum Islam Di Indonesia." 
yang berhak tidak akan terjadi sehingga keadilan benar-benar berpihak pada kepentingan sosial dan keadilan sosial adalah cita-cita luhur dalam kemanusiaan universal seluruh bangsa di dunia, termasuk Indonesia $^{37}$.

Makna adil secara etimologi menurut Nurcholish Majid adalah tengah atau pertengahan. Dan orang yang berbuat adil merupakan orang yang mampu mengambil keputusan tanpa berpihak dan menghormati hak asasi manusia. Hakikat HAM adalah membangun kebebasan manusiawi, termasuk kebebasan berpendapat. Jhon Stuart Mill seorang filosof kebebasan berpendapat “ boleh mengeluarkan pendapat dengan bebas asalkan secara lembut dan dalam batas kewajaran" 38 .

Kebebasan berpendapat ini selaras dengan misi kemanusiaan universal yang terdapat dalam syariat asasi agama-agama yang merupakan hal-hal dasar dalam ajaran kemanusiaan, yaitu Al-quran surah Al-Maidah:32." Barang siapa yang membunuh seorang manusia, bukan karena orang itu membunuh orang lain, atau bukan membuat kerusakan di muka bumi, maka seakan-akan dia membunub manusia selurubnya. Dan barang siapa yang memelihara kehidupan seorang manusia, maka seolab-olah dia telah memelihara kehidupan manusia semuanya". Prinsip ini ditegaskan oleh Nabi Muhammad SAW dalam pidato perpisahan (khutbatul wada $)^{39}$.

Membangun hak asasi manusia secara universal tidak dapat terealisasi bila hak asasi manusia belum dijadikan falsafah hidup, karenanya kesadaran tentang HAM menuntut adanya keyakinan dan penghayatan tentang makna dan tujuan kemanusiaan. Menjawab makna dan tujuan kemanuasiaan perlu ditegaskan bahwa rasa kemanusiaan haruslah berdasarkan rasa ketuhanan. Karena rasa kemanusiaan yang terlepas dari rasa ketuhanan akan mudah tergelincir pada praktik-praktik pemutlakan sesama seperti yang telah dilakukan oleh eksperimen-eksperimen komunis yang atheis (anti Tuhan) ${ }^{40}$.

Berikutnya Nurcholish Majid memberikan pandangan tentang toleransi, menurut Nurcholish Majid toleransi merupakan permasalahan kaidah dan kewajiban dalam menjalankan petunjuk tersebut. Toleransi dapat menciptakan sistematis hubungan sosial yang "enak" dalam setiap kelompok yang berbeda. Manfaat pelaksanaan toleransi merupakan anugrah dan hikmah atas pelaksanaan ajaran yang benar ${ }^{41}$.

\footnotetext{
${ }^{37}$ Ferry Irawan Febriansyah, "KEADILAN BERDASARKAN PANCASILA SEBAGAI DASAR FILOSOFIS DAN IDEOLOGIS BANGSA,” DiH Jurnal Ilmu Hukum 13, no. September 2004 (2017): 28-39.

38 Tony Rahmanto, "Kebebasan Berekspresi Dalam Perspektif Hak Asasi Manusia: Perlindungan, Permasalahan Dan Implementasinya Di Provinsi Jawa Barat," Jurnal HAM 7 (August 25, 2016): 45, https://doi.org/10.30641/ham.2016.7.70.

39 Fathurrahman, "Sejarah Pengkafiran Dan Marginalisasi Paham Keagamaan Di Melayu Dan Jawa."

${ }^{40}$ Febriansyah, "Keadilan Berdasarkan Pancasila Sebagai Dasar Filosofis Dan Ideologis Bangsa."

41 Ansari, "Implementasi Budaya Toleransi Beragama Melalui Pembelajaran Pendidikan Agama Islam Berwawasan Multikultural," Jurnal Attaqwa 8, no. 5 (2019): 55.

85 | Falasifa, Vol. 12 Nomor 2 September 2021
} 
Asripa

Devy Habibi Mubammad

Ari Susandi

Berhubungan dengan aspek toleransi yang menjadi prisip masyarakat madani, maka agama-agama yang murni berperan sebagai mediator atau penegak antara semua golongan umat manusia dan diharapkan akan menjadi saksi yang adil dan fair dalam hubungan antar golongan tersebut. Tidak heran jika umat islam terdahulu memiliki pemikiran terbuka serta bersikap inklusivistik sehingga tindakannnya selalu terlihat ramah dan bijak terhadap kelompok-kelompok lainnya ${ }^{42}$.

Paham pluralisme dalam pandangan Nurcholish Majid tidak cukup hanya diakui dan diterima sebagai kenyataan dalam masyarakat majemuk akan tetapi harus disertai dengan sikap yang tulus menerima kenyataan bahwa pluralisme merupakan nilai positif dan rahmat dari Tuhan kepada umat manusia untuk memperkaya pertumbuhan budaya yang beraneka ragam.. Agar lebih prinsip dalam mengurai kemajemukan kita perlu berkaca pada kehidupan masyarakat Madinah yang dikembangkan oleh Rosullah SAW. Dimana terdapat pergaulan yang harmonis antara kaum anshar, muhajirin dan yahudi sehingga tercipta hidup rukun dan damai serta saling gotong royong, hormat menghormati diantara mereka ${ }^{43}$.

Pluralitas bukan hanya tentang pemahaman masyarakat multikultural yang memiliki perbedaan suku dan agama. Hal ini hanya menimbulkan kesan fragmentasi. Pluralisme jangan diartikan sekedar kebaikan negatif yang dapat menyingkirkan fanatisme, lebih dari itu pluralisme merupakan pertalian kebhinekaan dalam sebuah ikatan perbedaan. Dalam konteks ini sesungguhnya percekcokan dalam masyarakat dianggap sebuah kewajaran. Karena tidak ada masyarakat yang benar-benar terbebas dari perselisihan seperti dalam adagium arab "Ridlanasi ghoyatun la tadruk" yang artinya bahwa sikap rela semua orang merupakan tujuan yang mustahil. Dan suatu kerancuan jika perselisihan terus meningkat sehingga timbul diskriminasi serta nengakhiri sebuah hubungan atau eks ${ }^{44}$.

\section{Analis Persamaan dan Perbedaan Pemikiran Gus Dur dan Nurcholish Majid}

Gus Dur dan Nurcholish Majid, keduanya adalah tokoh intelektual muslim yang menaruh perhatian cukup besar pada paham pluralisme di Indonesia. Menurut keduanya paham pluralisme perlu diterapkan di negeri ini mengingat bangsa Indonesia merupakan negara multikural dengan segala keanekaragamannya. Paham pluralisme penting diungkap secara jelas dan disebar luaskan demi menghindari pergesekan antar paham di berbagai struktur kelompok masyarakat. Paham pluralisme dalam perspektif pemikiran keduanya selaras dan sejalan dengan hakikat Pancasila yang merupakan

\footnotetext{
${ }^{42}$ Nasitotul Janah, "Merumuskan Kembali Teologi Hubungan Lintas Agama Di Tengah Pengalaman Kemajemukan (Sebuah Pendekatan Terhadap Ayat Makkiyyah Dan Madaniyyah)," Tarbiyatuna 7, no. 1 (2016): 119-43.

${ }^{43}$ Rijal, "Analisa Pemikiran Demokrasi Di Indonesia(Studi Pemikiran Abdurrahman Wahid Dan Nurcholish Majid)."

${ }^{44}$ Azzuhri, "Konsep Multikulturalisme Dan Pluralisme Dalam Pendidikan Agama."
} 
dasar dan falsafah hidup bangsa Indonesia. Keduanya juga menekankan pentingnya paham pluralisme dijadikan pandangan hidup sebagaimana hakikat Bhineka Tunggal Ika yang telah menjadi semboyan bangsa ini demi menjaga keutuhan $\mathrm{NKRI}^{45}$. Paham pluralisme keduanya terinspirasi dari agama islam sebagaimana tertera dalam Al-quran bahwa pluralisme adalah sunatullah yang tidak dapat dirubah oleh siapapun. Keduanya juga sepakat jika agama islam merupakan rahmatan Lil Alamin bagi seluruh umat dengan menjunjung tinggi kemanusiaan, menjaga toleransi dan berkeadilan sosial ${ }^{46}$.

Perbedaan pemikiran Gus Dur dan Nurcholish Majid didasari oleh latar belakang pendidikan keduanya. Pemikiran Gus Dur tentang Pribumisasi Islam yang mencoba menyelaraskan antara tuntunan syariat islam dengan kebudayaan lokal masyarakat selama tidak mengubah inti atau makna dari tuntunan syariat islam itu sendiri. Pribusasi Islam adalah upaya mempertahankan identitas keindonesiaan yang khas. Sedangkan Nurcholish Majid menguraikan pandangan tentang universalisme islam yang mengajarkan bahwa tuntunan agama islam dapat diterima diseluruh bagian dunia manapun, dan hal tersebut harus di dakwahkan sesuai dengan keadaan dan struktur masyarakat yang ada, sehingga visi dan misi dakwah mencapai tujuan sesuai dengan ajaran islam yang benar ${ }^{47}$.

\section{KESIMPULAN}

Plurarisme adalah keadaan masyarakat yang majemuk berkaitan dengan sistem sosial,politik dan kebudayaan yang berbeda di dalam suatu masyarakat. Pluralisme sebagai paham dan pandangan hidup juga mengakui dan menerima keberagaman dan kemajemukan dalam suatu kelompok masyarakat, maksudnya adalah menerima kemajemukan dari berbagai segi diantaranya dari segi agama, suku, ras dan adat istiadat. Pluralisme di Indonesia dilambangkan dengan motto Bhineka Tunggal Ika yang berarti bahwa negeri ini memiliki berbagai pulau, suku bangsa, ras dan agama tetapi tetap satu jua yaitu indonesia.sebab itulah indonesia memerlukan konsep pluralisme untuk tetap menjaga dan mempertahankan rasa persatuan dan kesatuan.

1. Gasasan pluralisme Gus Dur memiliki tujuan utama yaitu merealisasikan harmonisasi masyarakat Indonesia yang majemuk. Konsekuensi dari gagasannya ini membuat Gus Dur harus berada di garda depan ketika ada kekuatan yang ingin mencidrai kebhinekaan negeri ini, baginya kebhinekaan adalah sunatullah dan tidak satu pihakpun boleh mengubahnya.

\footnotetext{
${ }^{45}$ Yudi Setiadi, “Gagasan Pluralisme Gus Dur Dan Cak Nur Untuk Menangkal Gagasan Radikalisme," ICIGIs (International Conference on Islam and Global Issues) Postgraduate Programme State Islmic University Sultan Maulana Hasanuddin Banten Yaituteologis 1, no. 1 (2018): 44-45.

${ }^{46}$ Fakhri, "Wawasan Kerukunan Beragama Di Indonesia."

${ }^{47}$ Setiadi, "Gagasan Pluralisme Gus Dur Dan Cak Nur Untuk Menangkal Gagasan Radikalisme.”

87 | Falasifa, Vol. 12 Nomor 2 September 2021
} 
Asripa

Devy Habibi Mubammad

Ari Susandi

2. Paham pluralisme dalam pandangan Nurcholish Majid tidak cukup hanya diakui dan diterima sebagai kenyataan dalam masyarakat majemuk akan tetapi harus disertai dengan sikap yang tulus menerima kenyataan bahwa pluralisme merupakan nilai positif dan rahmat dari Tuhan kepada umat manusia untuk memperkaya pertumbuhan budaya yang beraneka ragam.

3. Dalam pandangan Gus Dur dan Nurcholish Majid, Pluralisme adalah sunatullah yang tidak dapat dirubah oleh siapapun. Keduanya juga sepakat jika agama islam merupakan rahmatan Lil Alamin bagi seluruh umat dengan menjunjung tinggi kemanusiaan, menjaga toleransi dan berkeadilan sosial. Perbedaan paham pluralisme kedua tokoh ini didasari oleh latar belakang pendidikan yang mana Gus Dur pernah belajar di Timur Tengah dan Eropa sedangkan Nurcholish Majid menjalani studinya di Chigago, Amerika serikat

\section{DAFTAR PUSTAKA}

Ansari. "Implementasi Budaya Toleransi Beragama Melalui Pembelajaran Pendidikan Agama Islam Berwawasan Multikultural.” Jurnal Attaqwa 8, no. 5 (2019): 55.

Azzuhri, Muhadis. "KONSEP MULTIKULTURALISME DAN PLURALISME DALAM PENDIDIKAN AGAMA." Tarbibyah 10, no. 9 (2012): 47-48.

Bauto, Laode Monto. "PERSPEKTIF AGAMA DAN KEBUDAYAAN DALAM KEHIDUPAN MASYARAKAT INDONESIA (Suatu Tinjauan Sosiologi Agama)." Jurnal Pendidikan Ilmu Sosial 23, no. 2 (2016): 11. https://doi.org/10.17509/jpis.v23i2.1616.

Efendi, Irfan. "Pluralisme Dalam Pendidikan Islam: Studi Pemikiran Prof. Dr. Nurcholish Madjid." Progresiva: Jurnal Pemikiran Dan Pendidikan Islam 7, no. 2 (2018): 114. https://doi.org/10.22219/progresiva.v7i2.13976.

Fakhri, Muhammad. "Wawasan Kerukunan Beragama Di Indonesia.” Jurnal Toleransi 1, no. 2 (2009): 141.

Fathurrahman, Oman. "SEJARAH PENGKAFIRAN DAN MARGINALISASI PAHAM KEAGAMAAN DI MELAYU DAN JAWA.” Jurnal Analisis XI (2011): 447-74.

Febriansyah, Ferry Irawan. "KEADILAN BERDASARKAN PANCASILA SEBAGAI DASAR FILOSOFIS DAN IDEOLOGIS BANGSA.” DiH Jurnal Ilmu Hukum 13, no. September 2004 (2017): 28-39.

Handoyo, Eko. Studi Masyarakat Indonesia. Semarang: Penerbit Ombak, 2015.

Hanipudin, Sarno, and Afif Anasrullah Alhaq. "Pemikiran Pendidikan Pluralisme KH. Abdurrahman Wahid." Jurnal Insania 22, no. 1 (2017): 38. 
Herdiawanto, Heri, Fokky Wasitaatmadja Fuad, and Jumanta Hamdayama. Spritualisme Pancasila. Jakarta: Prenadamedia Group, 2018.

Janah, Nasitotul. "Merumuskan Kembali Teologi Hubungan Lintas Agama Di Tengah Pengalaman Kemajemukan (Sebuah Pendekatan Terhadap Ayat Makkiyyah Dan Madaniyyah).” Tarbiyatuna 7 , no. 1 (2016): 119-43.

Khosiah, Nur, Reza Hilmi Luayyin, and David Prabowo. "POLIGAMI PERSPEKTIF MUHAMMAD ABDUH DAN MUHAMMAD SYAHRUR.” Jurnal Imtiyaz, 5, no. 02 (2021): 77-86.

Listiana, Akhmad Fatikhul Amin Abdullah, and Widjijanto. "PEMIKIRAN KH. ABDURRAHMAN WAHID TENTANG PLURALISME AGAMA DI INDONESIA TAHUN 1999-2001 (KH.” Jurnal Program Studi Sejarah STKIP PGRI Sidoarjo 2, no. 2 (2014): 264-80.

Muhammad, Devy Habibi. "Implementasi Pendidikan Humanisme Religiusitas Dalam.” Edumaspul Jurnal Pendidikan 4, no. 2 (2020): 122-31.

Naimah, Cik, and Ulil Hidayah. "Reorientasi Pendidikan Islam Untuk Harmonisasi Sosial: Hidden Curriculum Sebagai Sebuah Tawaran.” Proceedings of Annual Conference for Muslim Scholars, no. Seri 2 (2017): 726-32. http://proceedings.kopertais4.or.id/index.php/ancoms/article/view/73.

Nurdin, H. "Upaya Pemerintah Dalam Menghormati Dan Melindungi Ham Dengan Konsep the Rule of Law." Meraja Journal 1, no. 2 (2018): 9-15.

Priambodo, Sigit. "Motif Intervensi Arab Saudi Terhadap Perang Saudara Di Yaman.” Jurnal Analisis Hubungan Internasional 6, no. 1 (2017): 205-16. http://journal.unair.ac.id/download-fullpapersjahi0e78990c98full.pdf.

Rahmanto, Tony. "KEBEBASAN BEREKSPRESI DALAM PERSPEKTIF HAK ASASI MANUSIA: PERLINDUNGAN, PERMASALAHAN DAN IMPLEMENTASINYA DI PROVINSI JAWA BARAT.” Jurnal HAM 7 (August 25, 2016): 45. https://doi.org/10.30641/ham.2016.7.70.

Rambe, Safrizal. Sang Penggerak Nabdlatul Ulama K.H. Abdul Wahab Chasbullah Sebuah Biografi. Jakarta: Madani Institute, 2020. http://www.elsevier.com/locate/scp.

Rijal, Akhmad. "Analisa Pemikiran Demokrasi Di Indonesia(Studi Pemikiran Abdurrahman Wahid Dan Nurcholish Majid).” Jurnal Khitah:Kajian Islam ,Budaya Dan Humaniora 4, no. 2 (2021).

Romania, N. "Konstruksi Pengurus Pimpinan Wilayah Gerakan Pemuda Ansor Jawa Timurtentang Pluralisme Agama Menurut Gus Dur.” Kajian Moral Dan Kewarganegaraan 3, no. 4 (2016): 13911407. https://jurnalmahasiswa.unesa.ac.id/index.php/jurnal-pendidikankewarganegaraa/article/viewFile/16505/14997.

Rozi, Mohammad Fahrur. "PLURALISME DAN MULTIKULTURALISME DALAM

89 | Falasifa, Vol. 12 Nomor 2 September 2021 
Asripa

Devy Habibi Mubammad

Ari Susandi

MEMBANGUN MASYARAKAT MADANI; KAJIAN PARADIGMATIK." JUmal Al-Ibrah 11, no. 5 (2107).

Setiadi, Yudi. "Gagasan Pluralisme Gus Dur Dan Cak Nur Untuk Menangkal Gagasan Radikalisme.” ICIGIs (International Conference on Islam and Global Issues) Postgraduate Programme State Islmic University Sultan Maulana Hasanuddin Banten Yaituteologis 1, no. 1 (2018): 44-45.

Suhaili, Achmad. "Hak Asasi Manusia (HAM) Dalam Penerapan Hukum Islam Di Indonesia.” AlBayan: Jurnal Ilmu Al-Qur'an Dan Hadist 2, no. 2 (2019): 176-93. https://doi.org/10.35132/albayan.v2i2.77.

Susandi, Ari. "Pendidikan Life Skills Dalam Penanaman Nilai-Nilai Agama Islam Di Sekolah Dasar." Al-Insyiroh: Jurnal Studi Keislaman 6, no. 2 (2020): 95-111. https://doi.org/10.35309/alinsyiroh.v6i2.3867.

Tri Wahyudi Ramdhan. "Islam Nusantara : Pribumisasi Islam Ala NU." Al-Insyiroh: Jurnal Studi Keislaman 2 (2018): 73-91. http://ejournal.kopertais4.or.id/madura/index.php/alinsyiroh/article/view/3333.

Tualeka, M.Wahid Nur. "Gerakan Neomodernisme Islam Di Indonesia.” AL-Hikmah: Jurnal Studi Agama-Agama 1, no. 1 (2015): 1689-99. 